\title{
The Utility and Value of The Physiotherapy eSkills Training Online Resource During Work-integrated learning: A mixed methods study.
}

\author{
Elisabeth Preston \\ University of Canberra, Australia, Elisabeth.preston@canberra.edu.au \\ Cathy Chapple \\ Otago University, New Zealand, cathy.chapple@otago.ac.nz \\ Elizabeth Mayland \\ University of Wollongong, Australia, beth_mayland@uow.edu.au \\ Louise Ada \\ University of Sydney, Australia, louise.ada@sydney.edu.au \\ Leigh Hale \\ Otago University, New Zealand, leigh.hale@otago.ac.nz
}

Follow this and additional works at: https://nsuworks.nova.edu/ijahsp

Part of the Medicine and Health Sciences Commons

\section{Recommended Citation}

Preston E, Chapple C, Mayland E, Ada L, Hale L. The Utility and Value of The Physiotherapy eSkills Training Online Resource During Work-integrated learning: A mixed methods study.. The Internet Journal of Allied Health Sciences and Practice. 2020 Jan 01;18(2), Article 12.

This Manuscript is brought to you for free and open access by the College of Health Care Sciences at NSUWorks. It has been accepted for inclusion in Internet Journal of Allied Health Sciences and Practice by an authorized editor of NSUWorks. For more information, please contact nsuworks@nova.edu. 


\title{
The Utility and Value of The Physiotherapy eSkills Training Online Resource During Work-integrated learning: A mixed methods study.
}

\begin{abstract}
ABSTRACT

Purpose: The purpose of this study was to determine the use and value of the Physiotherapy eskills Training Online resource during work-integrated learning in naïve physiotherapy students. Method: A mixed methods study design was used. Participants: Forty-four final year physiotherapy students participating in neurological work-integrated learning units of study participated in this study. Intervention: Students had access to the Physiotherapy eSkills Training Online resource during their 6-week neurological workintegrated learning unit of study, which includes video footage and written information about 25 practical skills related to the physiotherapy management of stroke. Outcome Measures: Use of the Physiotherapy eskills Training Online resource was examined by recording the number of hits on the resource, the number of students who accessed it, the number of times each student accessed it, and the time it was accessed. Students' perception of the value of the resource was explored through semi-structured interviews. Results: There were 46 hits on the resource, by $13(30 \%)$ students during the neurological workintegrated learning unit of study. Ten students accessed the resource twice or more. Double the number of hits occurred outside of work hours compared with during work hours. Qualitative analysis revealed five themes regarding the low usage of the resource by students: content of the resource; learning style; learning behavior and expectations; technical issues; and practical issues. Conclusion: Use of the resource was low, with only a small number of students using the resource on a few occasions. Value of the resource could not be clearly established.
\end{abstract}

\section{Author Bio(s)}

Elisabeth Preston, BPhty, MAppSc, PhD, is an Assistant Professor in the Discipline of Physiotherapy, Faculty of Health, at the University of Canberra, Australia.

Cathy Chapple, BSc (Hons), Grad Dip Phty, MMPhty, PhD, is a Senior Lecturer in the School of Physiotherapy at the University of Otago, New Zealand.

Elizabeth Mayland, MSc, PhD, is a Lecturer in occupational therapy in the Faculty of Social Sciences at the University of Wollongong, Australia.

Louise Ada, BSc, GradDipPhty, MA, PhD, is an Emeritus Professor in the Discipline of Physiotherapy, Faculty of Health Sciences at University of Sydney, Australia.

Leigh Hale, BSc (Physio), MSC, PhD, FNZCP, is a Professor and Dean of the School of Physiotherapy at the University of Otago, New Zealand.

\section{Acknowledgements}

We would like to acknowledge the participants and clinical educators who volunteered to engage in this study. 


\title{
1IJAHSP \\ The Internet Joumnal of Allied Health Sciences and Practice
}

Dedicated to allied health professional practice and education

Vol. 18 No. 1 ISSN 1540-580X

\section{The Utility and Value of The Physiotherapy eSkills Training Online Resource During Work-integrated Learning: A mixed methods study.}

\author{
Elisabeth Preston ${ }^{1}$ \\ Cathy Chapple² \\ Elizabeth Mayland 3 \\ Louise Ada ${ }^{4}$ \\ Leigh Hale ${ }^{2}$
}

1. University of Canberra

2. Otago University

3. University of Wollongong

4. University of Sydney

Australia $1,3,4$ and New Zealand ${ }^{2}$

\begin{abstract}
Purpose: The purpose of this study was to determine the use and value of the Physiotherapy eSkills Training Online resource during work-integrated learning in naïve physiotherapy students. Method: A mixed methods study design was used. Participants: Forty-four final year physiotherapy students participating in neurological work-integrated learning units of study participated in this study. Intervention: Students had access to the Physiotherapy eSkills Training Online resource during their 6-week neurological work-integrated learning unit of study, which includes video footage and written information about 25 practical skills related to the physiotherapy management of stroke. Outcome Measures: Use of the Physiotherapy eSkills Training Online resource was examined by recording the number of hits on the resource, the number of students who accessed it, the number of times each student accessed it, and the time it was accessed. Students' perception of the value of the resource was explored through semi-structured interviews. Results: There were 46 hits on the resource, by 13 (30\%) students during the neurological work-integrated learning unit of study. Ten students accessed the resource twice or more. Double the number of hits occurred outside of work hours compared with during work hours. Qualitative analysis revealed five themes regarding the low usage of the resource by students: content of the resource; learning style; learning behavior and expectations; technical issues; and practical issues. Conclusion: Use of the resource was low, with only a small number of students using the resource on a few occasions. Value of the resource could not be clearly established.
\end{abstract}

Keywords: students, physical therapy specialty, education, stroke 


\section{INTRODUCTION}

Physiotherapy students are required to learn the practical skills needed for stroke rehabilitation in order to improve outcomes for stroke survivors. Until recently, practical skills in physiotherapy curricula have been taught by live demonstration, followed by practice and feedback, in a manner determined by classroom and time constraints. This leaves students to revise practical skills outside class time based on memory or on hand-written, potentially inaccurate, notes. E-learning may be a feasible strategy for overcoming these problems.

E-learning is now well accepted, improves confidence in skills, improves self-rated performance of skills, and is often preferred by learners over other modes of education.1-3 Furthermore, it can appear more authentic for learning practical skills because the clinical context can be embedded into video demonstrations and patient simulation. Video modelling is an effective tool for learning practical skills in a range of contexts: from learning gymnastics to retraining smiling in people after facial palsy.4,5 A randomised trial with medical students demonstrated that online simulation significantly increased the reliability of measuring haematocrit levels in blood, as well as improving students' perceptions regarding procedure difficulty. ${ }^{6}$ E-learning was also found to be highly satisfying by students ${ }^{6}$. An e-learning resource incorporating clinical scenarios, video demonstrations, and podcasts was found to be highly accessible and satisfactory in a population of surgeons, with 8000 hits registered over a 6-week period. ${ }^{7}$ Almost half the hits were accounted for by the clinical scenarios, suggesting a preference for learning in a "real" context.

In light of these studies, it is feasible that e-learning that embeds video demonstrations with therapist/patient interactions may be effective in enhancing learning of practical skills. It may provide physiotherapy students with control over practice conditions, thereby facilitating learning of skills related to stroke rehabilitation. In 2012, Preston et al examined the Physiotherapy eSkills Training Online resource (see Figure 1), which includes video simulations and supportive text for practical skills related to neurological physiotherapy, and found that students who had access to the resource scored higher on their practical examination than students who had usual teaching only (i.e. live demonstration of practical skills) ${ }^{8}$. In this study, the Physiotherapy eSkills Training Online resource was embedded in the neurological physiotherapy curriculum and utilized during weekly tutorials. Students' initial access to the resource occurred at least 12 months prior to students attending work-integrated learning and was the key resource for learning examinable practical skills. However, the study did not examine influence of the e-learning resource during work-integrated learning.

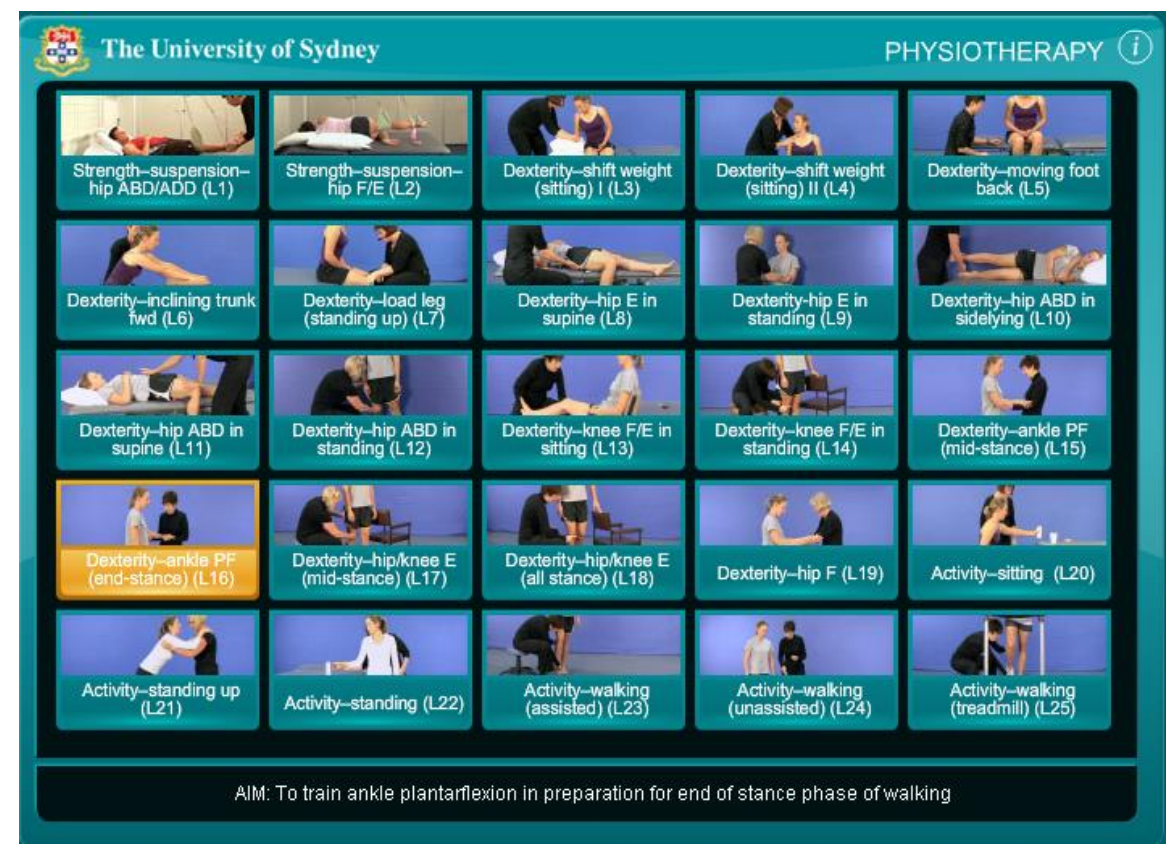

Figure 1. The Physiotherapy eSkills Training Online menu page where students can select the specific practical skill.

To determine whether the Physiotherapy eSkills Training Online resource can facilitate the transition from the academic to clinical setting, the resource was examined at a different university, where students were naïve to the resource. Specifically, this study aimed to examine the use and value of the Physiotherapy eSkills Training Online resource during work-integrated learning in resource-naïve physiotherapy students. 


\section{METHOD \\ Design}

A mixed methods study was carried out using a sequential explanatory strategy. ${ }^{9}$ Participants were recruited from students enrolled in the final year of a 4-year undergraduate physiotherapy program in New Zealand (not the university where the resource was developed), where $4^{\text {th }}$ year is primarily comprised of work-integrated learning. Four sites each offer $5 \times 6$-week neurological work-integrated learning units of study across the year. Ten of these 20 units of study were randomly chosen to evaluate the Physiotherapy eSkills Training Online resource. All physiotherapy students $(n=120)$ enrolled in the final year who were undertaking a neurological work-integrated learning unit of study at one of these sites were invited to participate. At the beginning of the unit of study, students attended a one-hour tutorial about the Physiotherapy eSkills Training Online resource. The tutorial consisted of 1) an overview of the resource and its components, 2) instructions on how to access it, and 3) demonstrations on how to use the resource to plan an intervention for a patient. This was the students' first exposure to the resource, and they were informed that they would have access to the Physiotherapy eSkills Training Online resource in addition to usual resources during the neurological work-integrated learning unit of study. A subset of participants $(n=8)$ undertook a semi-structured interview after completion of their neurological work-integrated learning unit of study. Ethical approval was obtained from the human research ethics committee of the university (Ref: SoP/EC/2015/10). All participants were provided with written information about the aims of the study and gave written informed consent.

\section{Participants}

All students attending the neurological work-integrated learning units of study chosen to test the resource were invited to participate. Purposive sampling to cover a range of academic ability (based on their neurological work-integrated learning unit performance and marks) was used to identify a subset of the total sample to undertake a semi-structured interview. Thirteen participants from the group randomised to the intervention group were approached by email and invited to participate in a short interview about their experiences with the Physiotherapy eSkills Training Online resource. Eight individuals agreed to participate.

\section{Setting}

Students were exposed to a range of settings during their neurological work-integrated learning unit of study. This included inpatient, outpatient, and community settings providing services for patients with acute and chronic neurological and general medical conditions.

\section{Intervention}

The Physiotherapy eSkills Training Online resource incorporates 88 practical skills related to neurological physiotherapy, including practical skills related to the management of stroke, cerebellar ataxia, Parkinson's disease, spinal cord injury, and traumatic brain injury. For each practical skill, the resource includes 1) an on-demand web-streamed high-quality video-clip of therapist-patient interaction; 2) text describing the aim, rationale, equipment, key points, common errors and methods of progression; and 3) a downloadable PDF document incorporating the online text information and a still image of the videoclip (Figure 2). For this study, participants had access to the 25 practical skills for management of stroke. Usual resources for the neurological clinical placement included lecture notes, manuals, and other recommended sources of information.

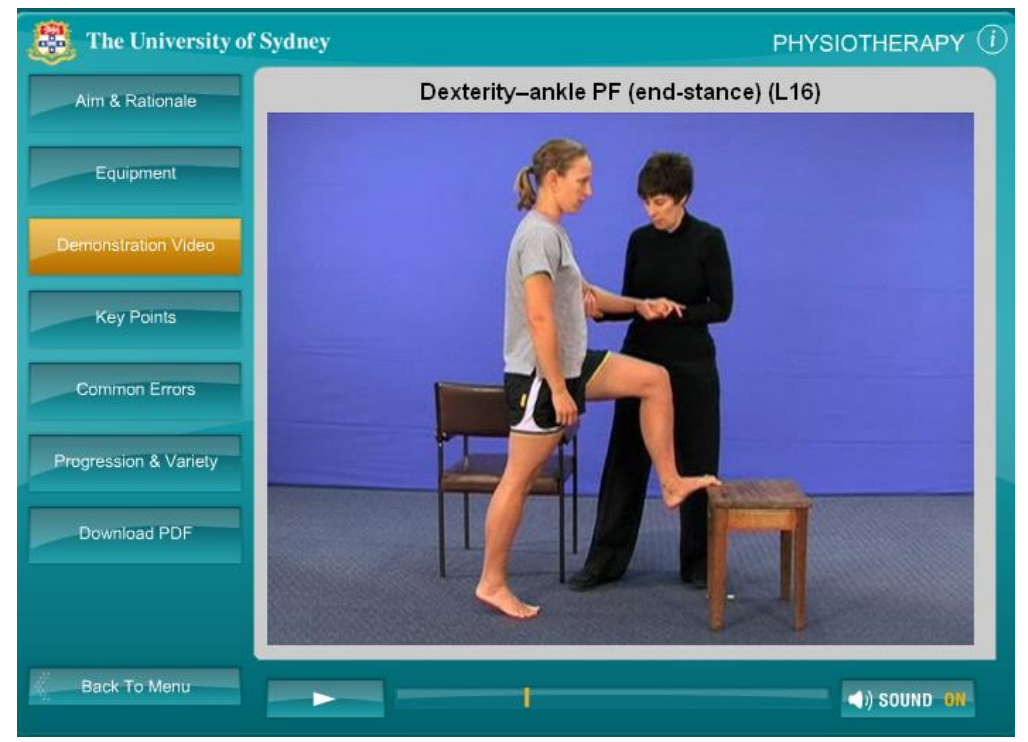


Figure 2. The webpage for an individual practical skill from the Physiotherapy eSkills Training Online resource, highlighting the demonstration video, and including menu buttons for the Aim and Rationale, Equipment, Key Points, Common Errors, Progression and Variety, and a Downloadable PDF.

\section{Outcome Measures}

Use of the Physiotherapy eSkills Training Online resource was examined by recording the number of hits on the resources, as well as the number of students who accessed it, the number of times it was accessed by each student, and the time of day it was accessed.

Students' perception of the value of the online learning resource, as well as their ability to integrate it into their learning, was explored through semi-structured interviews (see Figure 3 for interview questions). Interviews were conducted either in person $(n=4)$ or via skype $(n=4)$ for up to 30 minutes by a member of the research team not involved in clinical education (EM). They were audiotaped and transcribed verbatim. Students were recruited for interviews until data saturation was reached.
1. What was the most valuable resource for your neuro clinical placement?
2. Tell me how valuable the eskills resource was for your neuro clinical placement?
3. Describe any context/situations in which you found the eskills videos useful?
4. Describe the aspects of the eskills resource which you found valuable? In what way/s was the eskills resource valuable?
5. How, where, when did you access the eskills resource?
6. How could it be made more useful?
7. Are there any ways in which the eskills resource might be useful in the future?

Figure 3. Semi-structured interview questions.

\section{Data Analysis}

The number of hits on the resources, as well as the number of students who accessed it, the number of times it was accessed by each student, and the time it was accessed were presented.

The General Inductive Approach was used to analyse the interviews, and was conducted by the interviewer (EM)..$^{10}$ This method was selected because it is a pragmatic approach to data analysis in health settings in that analysis is driven by the objectives of the research. The transcripts were read to identify codes within the data related to the value of the Physiotherapy eSkills Training Online resource. Multiple codes were then collapsed and grouped into themes.

As a sequential explanatory strategy was used in this study, the quantitative data were first collected and analysed. This was followed by collection and analysis of the qualitative data with the aim of explaining the quantitative findings. ${ }^{9}$.

\section{RESULTS}

\section{Flow of Participants Through the Study}

One-hundred and twenty students were invited to participate in the study and 44 consented to participate. Thirteen students were invited to participate in the semi-structured interview and 8 agreed to participate. On average, students were 25.3 (SD 3.7) years old, and 38 (83\%) were female.

\section{Use of the Physiotherapy eSkills Training Online Resource}

The online resource had 46 hits. Thirteen students $(30 \%)$ accessed the online resource over the period of the 6-week neurological work-integrated learning unit of study: 3 students accessed the resource once, 5 students accessed the resource twice, and 5 students accessed the resource more than 3 times. Fifteen hits occurred during work hours (i.e. between 9 am and $5 \mathrm{pm}$ ) and 29 hits occurred outside of work hours.

\section{Value of the Physiotherapy eSkills Training Online Resource}

Given that very few students accessed the Physiotherapy eSkills Training Online resource, the focus of the semi-structured interviews shifted to an examination of why students did not use the resource. Analysis of the data from the semi-structured interviews revealed 5 themes: content of the resource; learning style; learning behavior and expectations; technical issues; and practical issues.

\section{Theme 1: Content of resource}

Students perceived that the the Physiotherapy eSkills Training Online resource was useful as a starting point for preparing for clinical placement. 
"It kind of can just give you a starting point, and, you know set your focus, and kind of help your targets and things." (Yvette)

"I actually did use the e-neuro learning as well, like a little look at it really quickly before I started... it was actually, yeah it was good to just have an idea of quick little things that you could do with patients. That was a good starting point, I think." (Kim)

However, students felt that the resource was not always relevant to the clinical population and had limited scope.

"It was a very, like, particular impairment that they had, like one aspect that was going wrong with their walking and you'd focus on that one thing, whereas a lot of the patients I was doing, we kinda like, expecially 'cause we're running a short amount of time we kinda have to do it more so we're doing the whole limb and working on everything together." (Bronwen)

\section{Theme 2: Learning style}

The learning style of students appeared to influence their decision about whether to use the Physiotherapy eSkills Training Online resource. A majority of students perceived the videos embedded in the resource to be useful in developing practical skills while on clinical.

"I liked that they kind of had...an actual patient, and they were demonstrating it. And so like, you get, take that visual, 'cause l'm quite a visual person. So, when I get a whole list of complicated instructions, it's hard for me to follow. I kind of zone out a little bit. So, seeing them actually performing the movements made a lot more sense for my brain, in terms of...perceiving how I was supposed to complete the treatment technique, than just reading through the list." (Clare)

However, students also felt they could rely on the clinical educator as the primary resource for developing practical skills during the neurological work-integrated learning unit of study because 1) they trusted their clinical educators' judgment, 2) their clinical educators set up the learning experience to give them ideas, 3) they did not trust their own interpretations of information, so they preferred to get feedback from more experienced clinicians, and 4) they valued the immediate feedback from a discussion.

"Our supervisor, she ran weekly tutes that we did with her...if she came up with...overall treatment ideas, then you can kinda tailor them towards your own patients, and kinda change them" (Bronwent)

Students also preferred the hands-on learning opportunities provided in a clinical context, including discussion with peers, to self-directed learning.

"Hands-on experience is better than a self-directed learning, if you didn't know where to start from. "(Mitchell)

\section{Theme 3: Learning behaviour and expectations}

Students consistently reported that the introduction of the Physiotherapy eSkills Training Online resource during clinical placements in $4^{\text {th }}$ year was too late. They felt it would have been valuable to have the resource during classroom learning in $2^{\text {nd }}$ and 3 rd year. This timing appears to have resulted in a lack of familiarity with the Physiotherapy eSkills Training Online resource which also limited its usefulness.

"Introducing [eSkills] a bit earlier in our education...gives us the opportunity to kind of get familiar with the system, and that by the time we're in our placement year and we want to pull out those resources, and revise them again, and it's a lot more natural for us to use, and it's not like trying to get familiar with a new system" (Clare)

"Just being familiar with it, and... having it available more frequently earlier on... l'd be far more inclined to use it." (Mitchell)

Students also reported a preference for relying on the knowledge gained during their undergraduate education, as well as in the personal knowledge of others, especially when they were busy and stressed on placement.

"While on placement, it's sort of the last thing you're thinking about...there's so much other stuff to do... and so many other things to worry about and probably by then you've gathered enough of an idea of exercise prescription to come up with stuff on your own" (Collin)

"You did sometimes have a lot of down time, but there was a lot of paperwork that I had to do, and if I was thinking up exercises, or something like that to do with patients' treatment planning, running exercise programmes and things, to print off for them, l'd tend to just come up with ones off the top of my head." (Natalie)

Students were also confident in their ability to implement practical skills and felt the resource would be useful if they had lacked confidence. 
"If I hadn't been doing so well, then I would have been looking up more resources. But because I was quite happy with how I was going, and my supervisor was really happy with how I was doing, I didn't necessarily feel the need to do a lot more study." (Genevieve)

"I think [the eSkills] looked like a good resource when you showed it...to us, but... between being well prepared here and going into a placement that didn't really require it, I just didn't use it" (Collin)

It also appears that the expectations of the clinical educators influenced the perceived usefulness of the resource. Students perceived that clinical educators provided structure for learning practical skills during the clinical placement and did not expect students to be independent in coming up with practical skills for managing their patients.

"So the students are allowed to observe, but not really run something themselves and then by the time you are allowed to run something yourself, it's... been set up for you already...so when it came time to picking exercises and so on which the e-skills would've been good for, they [the patients] mostly already had a programme set up, that I was just continuing." (Collin)

\section{Theme 4: Technical issues}

Students identified technical elements of the Physiotherapy eSkills Training Online resource that were both useful and not useful. Students felt that the inclusion of video footage and PDF outline were useful for their learning on clinical placement, and while some found the resource easy to navigate, some students found it more difficult to navigate.

"I liked how I could watch it and look through it and you also, how you had the wee tips and things like that to look at, as to what kind of compensatory movements they might do and what to look out for." (Bronwen)

"When I like clicked on the PDF, l'm like ah this laid out really nicely, like this'd be perfect, 'cause it tells you what it's doing, how it was gonna do it, and you'd have all the steps there" (Katie)

Students also offered ideas about ways to improve the resource for the future.

"Maybe like having like a mobile phone app or something like that, where you could access it on your phone. (Bronwen)

\section{Theme 5. Practical issues}

Students perceived several difficulties in accessing the Physiotherapy eSkills Training Online resource. The identified two main reasons were 1) The link to the resource was not provided in timely manner, and 2) There was limited access to computers and/or internet at the clinical site placement.

"I didn't actually receive access to [eSkills] until about half-way through the placement. So, we'd been told about it before the placement...but for some reason or another we didn't receive access until, like the end of week two, beginning of week three... and by that stage...everything else I was doing was working well for me." (Genevieve)

Students also felt that there were sufficient resources provided or recommended by the clinical educators, such that they did not need to use the Physiotherapy eSkills Training Online resource. They also reported that there was insufficient time during the clinical placement to utilise the resource.

"And in the evenings, when I otherwise would have probably been looking stuff up like that, I tended to be more researching the literature, regarding things, rather than coming up with specific exercises" (Natalie)

Researcher: "So you were more reviewing patient notes rather than looking up resources?"

"Yeah, case presentations, and then even just...keeping up with the clinical diaries and the portfolios and the feedback, and everything you've got to do on top of that. "(Collin)

"Our supervisor, she ran weekly tutes [and]...if she came up with, like, just overall treatment ideas, then you can tailor them towards your...own patients, and change them and things like that. So I used that a lot, also, just looking up articles and things like that, like PEDRO I used a lot, just, especially like the sensory training and things like that, to look up ideas that they use and things like that. And used that with my patients. And then...talking to the other students and things like that and talking to them about what treatment ideas they'd do with someone that had a certain impairment and ideas like that." (Bronwen)

\section{DISCUSSION}

This study examined the use and value of the Physiotherapy eSkills Training Online resource during a neurological workintegrated learning unit of study in resource-naïve physiotherapy students. Only a small number of students accessed the resource on a few occasions. The majority of access occurred outside of work hours. Students reported that they did not use the Physiotherapy eSkills Training Online resource for several reasons: the content of the resource was not always relevant to their specific population; their learning style meant they preferred to rely on their clinical educator and hands-on experience; and felt that they had sufficient other resources provided by the university and/or clinical educators. Furthermore, 
they lacked familiarity with the resource and had no expectation from the clinical educators regarding its use; had limited access to computers and/or the internet; and were not provided with sufficient time at work to access the resource.

In this study, the Physiotherapy eSkills Training Online resource was introduced to students at the commencement of their neurological work-integrated learning unit of study in their final year. At this time, students had already completed all theoretical units of study related to neurological physiotherapy. While there were practical issues making access to the resource difficult, problems such as lack of familiarity and lack of expectation in using the Physiotherapy eSkills Training Online resource may have been the result of the resource not being embedded in the neurological academic curriculum prior to the neurological work-integrated learning unit of study. For example, at the university where the resource was developed and embedded in the neurological academic curriculum, 112 students made 4,498 hits on Physiotherapy eSkills Training Online resource over one academic semester, ie, 40 hits per student. ${ }^{11}$ In addition, when it is aligned with the learning outcomes of an academic unit, students have significant benefit in terms of performance of their skills during examination, and perceive that the resource would be useful during the neurological work-integrated learning unit of study. ${ }^{8}$ This is consistent with the findings of similar studies in physiotherapy, where online resources have been found to be useful for performance of practical skills when the resource is embedded in the unit of study.12 Adult learners are motivated by learning resources that are perceived to be relevant and have real-world application. ${ }^{13}$ It is possible that students need to be familiar with a resource prior to their work-integrated learning unit of study to perceive its relevance and value and therefore use it in a clinical context.

Students perceived clinical educators to be the most useful resource for developing practical skills during the neurological work-integrated learning unit of study. Graduate physiotherapists most frequently use clinical experience to inform clinical decision making, more so than research evidence, so it is unsurprising that students opt for clinical educator experience as the primary resource to support their clinical decisions as well. ${ }^{14}$ During the work-integrated learning unit of study, it is likely that students were in the cognitive stage of learning the practical skills required for neurological physiotherapy. ${ }^{15}$ During the cognitive phase of learning students experiment with different ways to perform new skills, and then utilise feedback to find the most effective strategy ${ }^{14}$. The presence of a clinical educator ensures that feedback is available. It is clear that learning requires timely and specific feedback for students to improve performance. ${ }^{16}$ The presence of an expert also promotes learning. ${ }^{17}$ Specifically, social interaction with an expert, in this case a clinical educator, enhances learning more than learning by ones' self (i.e. using the Physiotherapy eSkills Training Online resource independently out of work hours). The resource was not embedded in the academic curriculum, and thus students had not established it relevance. Therefore, the students considered the clinical educator to be a sufficient resource to promote their learning of practical skills.

\section{Strengths and limitations}

We assumed that students would use the resource and find it useful. Given that they did not use it very much, the focus of the study shifted to exploring why they did not use it, so that this situation could be rectified in the future. A strength of the study was that semi-structured interviews were conducted by a researcher not involved in the academic assessment of students. This allowed a sense of anonymity for students that may have promoted more honesty during the interview than if interviews had been conducted by a member of staff known to the students. Similarly, expression of opinions may have been restrained had the interview been in a focus group. A limitation is that students who were interviewed were the students who had chosen to use the Physiotherapy eSkills Training Online resource at least once. Therefore, the data may reflect the opinions of a sub-set of students that is not representative of all students. For instance, it may be that students who were aiming for outstanding achievement during the work integrated learning unit of study chose to use the resource, or reciprocally, it could be that students who were underperforming considered using additional resources to assist them.

\section{CONCLUSION}

While the Physiotherapy eSkills Training Online resource has been previously demonstrated to be a useful resource for developing practical skills in physiotherapy students prior to work-integrated learning, it was not used by resource-naïve physiotherapy students during their neurological work integrated learning unit of study. ${ }^{8}$ As such, the value of the resource during work integrated learning could not be established. Semi-structured interviews revealed that students perceived the low usage to be related to the content of the resource, learning style, learning behaviours, and expectations and practical issues. The content of the resource was not always perceived to be related to the clinical caseload, and students preferred direct contact with clinical educators and hands-on practice in terms of their learning style. The late introduction of the online resource meant that students had not incorporated it into their learning behaviours and expectations of learning, and lack of computer access and time restrictions created a practical barrier to using the resource. If these barriers could be overcome, it is possible that use of the Physiotherapy eSkills Training Online resource may be higher. For example, if there is an expectation that students will benefit from an online resource during learning away from the university, then ensuring accessibility during clinical hours is important. Furthermore, online resources that are designed to be useful during workintegrated learning should be embedded in a preparatory academic unit of study, so that access as part of learning becomes habitual, and that the relevance and value of the resource can be established by the student. 


\section{REFERENCES}

1. Hills DJ RT, Kelly B, Heathcote S. Outcomes from the trial implementation of a multidisciplinary online learning program in rural mental health emergency care. Education for Health: Change in Learning and Practice 2010;23(1):1-12.

2. Gormley G CK, Boohan M, Bickle IB, Stevenson M. Is there a place for e-learning in clinical skills? A survey of undergraduate Medical students' experiences and attitudes Medical Teacher. 2009 31:6-12.

3. Newman C BT, Dunn S, Cashin A Preferences for continuing education through existing electronic access for Australian Nurse Practitioners and its implication in prescribing potential. . Collegian 2009 16:79-83.

4. Dowrick P. A review of self modeling and related interventions. Applied \& Preventive Psychology 1999;8:23-39.

5. Coulson SE, O'Dwyer NJ, Croxson GR Physiotherapy rehabilitation of the smile after long-term facial nerve palsy using video self-modeling and implementation intentions Otolaryngol Head Neck Surg 2006 134 48-55

6. Moreno-Ger P, Bustamante J, Fernández-Galaz C, Fernández-Manjón B, Comas-Rengifo MD Application of a low-cost web-based simulation to improve students' practical skills in medical education. International Journal of Medical Informatics 2010 7(9):459-467.

7. McHugh M CM, Dimitrov B, Cowan S, Tierney S, Humphreys H, Hill A A Targeted E-Learning Program for Surgical Trainees to Enhance Patient Safety in Preventing Surgical Infection. Journal of Continuing Education in the Health Professions 2010 30(4):257-259.

8. Preston E, Ada L, Dean CM, Stanton R, Waddington G, Canning CG. The Physiotherapy eSkills Training Online resource improves performance of practical skills: a controlled trial. . BMC Medical Education 2012;12 (119).

9. Creswell JW. Research design: Qualitative, quantitative, and mixed methods approaches. Thousand Oaks, CA: Sage Publications 2009.

10. Thomas D. A General Inductive Approach for Analyzing Qualitative Evaluation Data American Journal of Evaluation 2006;27 (2): 237-246.

11. Canning C. Physiotherapy Eskills Training Online. . Australian Physiotherapy Association Conference proceedings 2009.

12. Fary R.E, Jordan J.E, Gardner P, Chua J, Payne C, Briggs, A.M Assessing implementation readiness and success of an e-resource to improve prelicensure physical therapy workforce capacity to manage rheumatoid arthritis Journal of Orthopaedic and Sports Physical Therapy 2017 47(9):652-663.

13. Knowles M. The Adult Learner: A Neglected Species. 3rd ed Housten: Gulf Publishing. 1984.

14. Manns PJ NA, Darrah J Cross-sectional study to examine evidence-based practice skills and behaviors of physical therapy graduates: is there a knowledge-to-practice gap? . Physical Therapy. 2015; 95(4):568-578.

15. Fitts PM PM. Human Performance. Belmont: Brooks/Cole Pub Co. 1967.

16. Trowbridge MaC, H An Experimental Study of Thorndike's Theory of Learning The Journal of General Psychology 1932 7(2).

17. Vygotsky LS. Mind in Society. Harvard University Press. 1978. 